\title{
Arterial pulse wave velocity, inflammatory markers, pathological GH and IGF states, cardiovascular and cerebrovascular disease
}

\author{
Michael R Graham' \\ Peter Evans ${ }^{2}$ \\ Bruce Davies' \\ Julien S Baker' \\ 'Health and Exercise Science \\ Research Unit, Faculty of Health \\ Sport and Science, University of \\ Glamorgan, Pontypridd, Wales, United \\ Kingdom; ${ }^{2}$ Royal Gwent Hospital, \\ Newport, Gwent, United Kingdom
}

Correspondence: Michael R Graham Health and Exercise Science Research Unit, Faculty of Health Sport and Science, University of Glamorgan, Pontypridd,

Wales, United Kingdom

Tel +44 I 443482873

Fax +44 I443482285

Email drgraham@glam.ac.uk

\begin{abstract}
Blood pressure (BP) measurements provide information regarding risk factors associated with cardiovascular disease, but only in a specific artery. Arterial stiffness (AS) can be determined by measurement of arterial pulse wave velocity (APWV). Separate from any role as a surrogate marker, AS is an important determinant of pulse pressure, left ventricular function and coronary artery perfusion pressure. Proximal elastic arteries and peripheral muscular arteries respond differently to aging and to medication. Endogenous human growth hormone (hGH), secreted by the anterior pituitary, peaks during early adulthood, declining at $14 \%$ per decade. Levels of insulin-like growth factor-I (IGF-I) are at their peak during late adolescence and decline throughout adulthood, mirror imaging GH. Arterial endothelial dysfunction, an accepted cause of increased APWV in GH deficiency (GHD) is reversed by recombinant human (rh) GH therapy, favorably influencing the risk for atherogenesis. APWV is a noninvasive method for measuring atherosclerotic and hypertensive vascular changes increases with age and atherosclerosis leading to increased systolic blood pressure and increased left ventricular hypertrophy. Aerobic exercise training increases arterial compliance and reduces systolic blood pressure. Whole body arterial compliance is lowered in strength-trained individuals. Homocysteine and C-reactive protein are two inflammatory markers directly linked with arterial endothelial dysfunction. Reviews of GH in the somatopause have not been favorable and side effects of treatment have marred its use except in classical GHD. Is it possible that we should be assessing the combined effects of therapy with rhGH and rhIGF-I? Only multiple intervention studies will provide the answer.
\end{abstract}

Keywords: arterial pulse, wave velocity, arterial stiffness, growth hormone, insulin-like growth factor, physiology

\section{Introduction}

Arterial distensibility and arterial compliance decrease with age and atherosclerosis leading to increased systolic blood pressure (SBP) and a widening of the pulse pressure (PP), resulting in left ventricular hypertrophy, a risk factor for cardiovascular disease (CVD) (Laogun and Gosling 1982; Riley et al 1986).

Early changes in vascular properties precede the development of coronary artery disease (CAD) and hypertensive heart disease (Cohn et al 1995). Arterial pulse wave velocity (APWV) and compliance alterations occur early in the course of essential hypertension in relation to other CVD risk factors (Brinton et al 1996). Physical properties of the vasculature require a measurement of the distending force (ie, BP), using pressure transducers at relevant sites (Asmar et al 1995). The form of the pulse wave through the walls of the blood vessels is affected by the mechanical properties of the vessels. Pulse-wave augmentation results from reflections of the pulse wave at distal sites (such as bifurcations), such that the forward wave and reflected wave superimpose producing the typical arterial pulse wave, which differs at different sites 
(O'Rourke 1999). The PWV and the amplitude of reflected waves are increased in stiffer arteries, and are reduced with increased arterial compliance (O'Rourke et al 2001). These features are dependent on a number of hemodynamic variables, including heart rate and PP (Wilkinson et al 2002a). Therefore, measurements of augmentation are generally corrected for PP and expressed as an "augmentation index" $\left(\mathrm{AI}^{\mathrm{x}}\right)$.

These measurements are also affected by vasoactive drugs (O’Rourke 1992; Kelly et al 2001; Wilkinson et al 2001a) and by insulin (Westerbacka et al 1999) and are sensitive to inhibition of nitric oxide synthase (Kinlay et al 2001; Stewart et al 2003). The application of these measurements in concert with vasodilators has been proposed as an alternative approach for the measurement of vascular function (Wilkinson et al 2002b).

\section{Arterial pulse wave velocity}

Measurement of arterial wave propagation as an index of vascular stiffness and vascular health dates back to the early part of the last century (Bramwell and Hill 1922).

The arrival of the pulse wave at two different arterial sites is timed, and from estimates of the length of blood vessels between these sites (by measuring the distances at overlying skin sites), the velocity of this wave is calculated in m.s ${ }^{-1}$ (O'Rourke 1999; Lehmann 1999; Wilkinson et al 1999). Subtleties come in correctly estimating the intervening distances. This provides a reliable measure of arterial stiffness; at a given blood pressure, the stiffer the vessel, the less time it takes for the pulse wave to travel the length of the vessel. The APWV, especially of the aorta, has emerged as an important independent predictor of cardiovascular events. APWV increases with stiffness and is defined by the Moens-Korteweg equation, $\mathrm{PWV}=\sqrt{ }(E h / 2 P R)$, where $E$ is Young's modulus of the arterial wall, $h$ is wall thickness, $R$ is arterial radius at the end of diastole, and $P$ is blood density (Lehmann 1999).

The time delay between the arrival of a predefined part of the pulse wave, such as the foot, at two points is obtained either by simultaneous measurement, or by gating to the peak of the R-wave of the ECG. The distance travelled by the pulse wave is measured over the body surface and APWV is then calculated as distance divided by time $\left(\mathrm{m} . \mathrm{s}^{-1}\right)$ and depends on anatomical variation. The abdominal aorta tends to become more tortuous with age potentially leading to an underestimation of APWV (Wenn and Newman 1990). APWs can also be detected by using Doppler ultrasound (Sutton-Tyrrell et al 2001) or applanation tonometry (Wilkinson et al 1998b) where the pressure within a small micromanometer flattened against an artery equates to the pressure within the artery. Increases in distending pressure increase APWV (Bramwell and Hill 1922). Therefore, account should be taken of the level of BP in studies that use APWV as a marker of cardiovascular risk.

An increase in HR of 40 beats per minute was shown to increase APWV by $>1 \mathrm{~m} / \mathrm{s}$ (Lantelme et al 2002). Also acute increases in heart rate (HR) markedly lower arterial distensibility, occurring in both large and middle-size muscular arteries within the range of "normal" HR values (Giannattasio et al 2003). Raised APWV occurs with a range of established cardiovascular risk factors (Lehmann et al 1998) including age (Bramwell et al 1923; Vaitkevicius et al 1993), hypercholesterolemia (Lehmann et al 1992a), type II diabetes mellitus (DM) (Lehmann et al 1992b), and sedentary lifestyle (Vaitkevicius et al 1993). In hypertension, carotid-femoral APWV is an independent predictor of both cardiovascular and all-cause mortality (Laurent et al 2001). The odds ratio for a $5 \mathrm{~m} . \mathrm{s}^{-1}$ (a relatively large change in PWV) increment in PWV was 1.34 for all-cause mortality and 1.51 for cardiovascular mortality. In contrast, PP was independently related to all-cause mortality but only marginally related to cardiovascular mortality, indicating that specific assessment of arterial stiffness, with APWV, may be of greater value in the evaluation of risk. APWV ranged from 9 to $13 \mathrm{~m} . \mathrm{s}^{-1}$, whereas recently quoted values of carotid-femoral PWV in healthy individuals with average ages of 24 to 62 years ranged from around 6 to $10 \mathrm{~m} \cdot \mathrm{s}^{-1}$ (O'Rourke et al 2002). In hypertensive subjects without a history of overt cardiovascular disease APWV also predicts the occurrence of cardiovascular events independently of classic risk factors (Boutouyrie et al 2002). Aortic APWV $>13 \mathrm{~m} . \mathrm{s}^{-1}$ is a particularly strong predictor of cardiovascular mortality in hypertension (Blacher et al 1999a). Carotid-femoral APWV significantly increases at a faster rate in treated hypertensives than in normotensive controls, although where BP was well controlled APWV progression was attenuated (Benetos et al 2002).

Aortic APWV, assessed by using Doppler flow recordings, independently predicts mortality in patients with endstage renal failure (ESRF), a population with a particularly high rate of cardiovascular disease (Blacher et al 1999b; Safar et al 2002). The benefit associated with BP control in ESRF, by the use of anti-hypertensives, was independently related to change in aortic APWV, such that a reduction in APWV of $1 \mathrm{~m} . \mathrm{s}^{-1}$ was associated with a relative risk of 0.71 for all-cause mortality (Guerin et al 2001).

\section{The mechanisms of arterial stiffness}

Windkessel theory treats the circulation as a central elastic reservoir (the large arteries), into which the heart pumps, and 
from which blood travels to the tissues through relatively nonelastic conduits (Oliver and Webb 2003). The elasticity of the proximal large arteries is the result of the high elastin to collagen ratio in their walls, which progressively declines toward the periphery. The increase in arterial stiffness that occurs with age (Hallock and Benson 1937) is the result of progressive elastic fibre degeneration (Avolio et al 1998). The aorta and its major branches are large arteries, which can be differentiated from the more muscular conduit arteries, such as the brachial and radial arteries. The elasticity of a given arterial segment is not constant but instead depends on its distending pressure (Hallock and Benson 1937; Greenfield and Patel 1962). As distending pressure increases, there is greater recruitment of relatively inelastic collagen fibres and, consequently, a reduction in elasticity (Bank et al 1996). In addition to collagen and elastin, the endothelium (Wilkinson et al 2002a) and arterial wall smooth muscle bulk and tone (Bank et al 1999) also influence elasticity. A number of genetic influences on arterial stiffness have also been identified. Polymorphic variation in the fibrillin-1 receptor (Medley et al 2002), angiotensin II type-1 receptor and endothelin receptor (Lajemi et al 2001a) genes are related to stiffness. The angiotensin-converting enzyme (ACE) I/D polymorphism has been associated with stiffness (Balkestein et al 2001), but not consistently (Lajemi et al 2001b). As a consequence of differing elastic qualities and wave reflection, the shape of the arterial waveform varies throughout the arterial tree. In healthy, relatively young subjects, whereas mean arterial pressure (MAP) declines in the peripheral circulation, SBP and PP are amplified (Kroeker and Wood 1955). This amplification is exaggerated during exercise (Rowell et al 1968) but reduces with increasing age (Wilkinson et al 2001). APWV in the brachial artery has been shown to increase with age, indicative of worsening arterial compliance (Avolio et al 1983). However, brachial artery PWV (baPWV) has been reported to change less with age than APWV in the aorta or lower limb arteries. In contrast, the assessment of distensibility using APWV is indirect and potentially affected by changes in blood flow and MAP that reflect changes in more distal resistance vessels (Nichols and O'Rourke 1998). Atherosclerosis, hypertension, and diabetes produce macro- and micro-vascular changes that are reflected in vascular function and physical properties before the development of overt clinical disease (Berenson et al 1992). Endothelial cells continuously release nitric oxide (NO), which is synthesized by the endothelial isoform of NO synthase (NOS-III) (Moncada et al 1991; Förstermann et al 1993). NOS-III activity is stimulated by chemical agonists such as serotonin, acetylcholine (ACh) and bradykinin (Furchgott 1984; Cocks et al 1985; Newby and Henderson 1990) and by flow-induced shear forces on the endothelial cell wall (Pohl et al 1986; Busse and Pohl 1993; Meredith et al 1996). Endothelium-derived NO diffuses toward the underlying vascular smooth muscle, producing relaxation. The vascular endothelium, therefore, plays a central role in the modulation of arterial smooth muscle tone and thus influences large-artery distensibility and the mechanical performance of the cardiovascular system (Ramsey et al 1995). By improving arterial elasticity, endothelium-derived NO reduces the arterial wave reflection and reduces left ventricular work and the pulse pressure within the aorta. In addition, exogenous acetylcholine and glyceryl trinitrate (GTN) both increase arterial distensibility, the former mainly through NO production. This may help explain why conditions that exhibit endothelial dysfunction are also associated with increased arterial stiffness. Therefore, reversal of endothelial dysfunction or drugs that are large-artery vasorelaxants may be effective in reducing large-artery stiffness in humans, and thus cardiovascular risk. GTN reduces brachial artery stiffness and decreases wave reflection (Yaginuma et al 1986). Moreover, drugs that stimulate endothelial NO release, such as $\mathrm{ACh}$, also reduce muscular artery stiffness in vivo (Ramsey et al 1995; Joannides et al 1997).

\section{Specific studies in exercise}

Changes in APWV in dynamic exercise in normal individuals, may provide a reference point against which to compare the effect of disease states and the basis for evaluation of their component mechanisms (Naka et al 2003). Aerobic exercise training increases arterial compliance and reduces SBP and in cross-sectional studies, aerobically trained athletes have a higher arterial compliance than sedentary individuals (Mohiaddin et al 1989; Kingwell et al 1995; Vaitkevicius et al 1993). Hammer throwers recorded significantly higher compliance in the radial artery of the dominant arm relative to both the contra-lateral arm and to an inactive control group (Giannattasio et al 1992). This could be explained by the dynamic nature of the action.

A single bout of cycling exercise increased whole body arterial compliance by mechanisms suggesting vasodilation. In exercising muscles, factors including local increases in temperature, carbon dioxide, acidity, adenosine, $\mathrm{NO}$ and magnesium and potassium ions may all contribute to local vasodilation (Kingwell et al 1997a). Four weeks of cycle training, in sedentary individuals, significantly increased forearm blood flow and blood 
viscosity, suggesting an increased basal production of nitric oxide from the forearm. The elevated shear stress in this vascular bed may contribute to endothelial adaptation (Kingwell et al 1997b). Both the proximal aorta and the leg arteries were significantly stiffer and contributed to significantly higher aortic characteristic impedance in strength-trained athletes (Bertovic et al 1999). However, large-artery stiffening associated with isolated systolic hypertension (ISH) is resistant to modification through short-term aerobic training (Ferrier et al 2001). In subjects 70 to 100 years old, aortic APWV was a strong, independent significant predictor of cardiovascular death, whereas systolic blood pressure or pulse pressure was not (Meaume et al 2001). GTN, an exogenous NO donor significantly increased brachial artery area and compliance and significantly decreased pulse wave velocity (Kinlay et al 2001). In contrast to the beneficial effect of regular aerobic exercise, resistance training does not exert beneficial influences on arterial wall buffering functions (Miyachi et al 2003). However, several months of resistance training "reduced" central arterial compliance in healthy men (Miyachi et al 2004). The 3-hydroxyl3-methyl coenzyme A reductase inhibitors (statins), significantly reduced total and low-density lipoprotein cholesterol and triglyceride levels and increased high density lipoprotein cholesterol and significantly lowered APWV (Ferrier et al 2002). Atorvastatin significantly reduced arterial stiffness in patients with rheumatoid arthritis, possibly through an anti-inflammatory action (Van Doornum et al 2004). Age, blood pressure, body mass index (BMI), triglycerides, blood glucose and uric acid were shown to be significant variables for baPWV in both genders (Tomiyama et al 2003). Central aortic stiffness would appear to be the initial main site for promotion of the development of coronary atherosclerosis and ischemic heart disease (McLeod et al 2004).

\section{Physiology of growth hormone (GH)}

The ability of the somatotroph cells in the anterior pituitary to synthesize and secrete the polypeptide, human growth hormone ( $\mathrm{hGH}$ ) are determined by a gene called the Prophet of Pit-1 (PROP1). When GH is translated, 70\%-80\% is secreted as a 191-amino-acid, 4-helix bundle protein and $20 \%-30 \%$ as a less abundant 176 -amino-acid form (Baumann 1991) (Figure 1). Hypothalamic-releasing and hypothalamic-inhibiting hormones acting via the hypophysial portal system control the secretion of GH, which is secreted into the circulation (Melmed 2006).

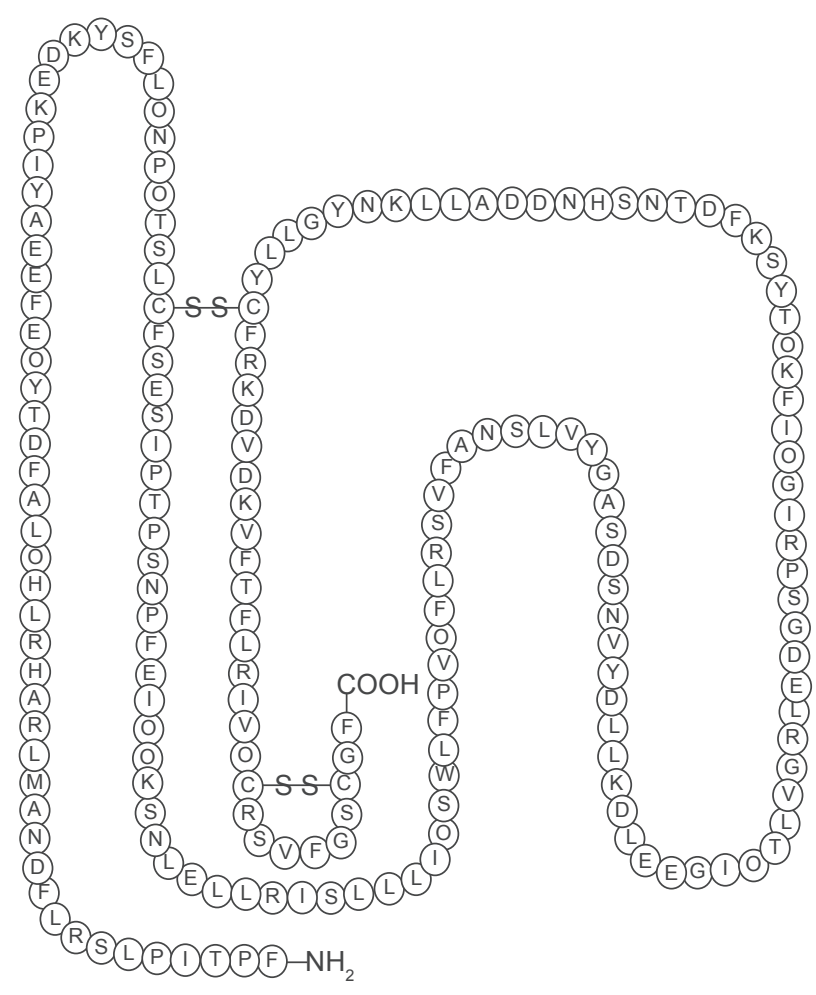

Figure I The structure of human growth hormone. Human growth hormone in its correct 22-kD-hGH form. Three-dimensional structure, generated from the protein data base SWISS PROT. Structural data supplied with the help of the program RasMol. The n-terminal amino acid is at the bottom right hand corner. The disulphide bridges make the molecule a 3 dimensional structure (the sequence range is missing on the $20 \mathrm{kDa}$ hGH variant).

In healthy persons, the GH level is usually $<0.2 \mu \mathrm{g} . \mathrm{L}^{-1}$ throughout most of the day. There are approximately 10-12 intermittent bursts in a 24-hour period, mostly at night, when the level can rise to $30 \mu \mathrm{g} . \mathrm{L}^{-1}$ (Melmed 2006). GH secretion declines at $14 \%$ per decade from the age of 20 years (Iranmanesh et al 1991).

$\mathrm{GH}$ action is mediated by a $\mathrm{GH}$ receptor, which is expressed mainly in the liver and is composed of dimers that change conformation when occupied by a GH ligand (Brown et al 2005).

Cleavage of the $\mathrm{GH}$ receptor provides a circulating $\mathrm{GH}$ binding protein (GHBP), prolonging the half-life and mediating the transport of GH. Growth hormone activates the growth hormone receptor, to which the intracellular Janus kinase 2 (JAK2) tyrosine kinase binds. Both the receptor and JAK2 protein are phosphorylated, and signal transducers and activators of transcription (STAT) proteins bind to this complex. STAT proteins are then phosphorylated and translocated to the nucleus, which initiates transcription of growth hormone target proteins (Argetsinger et al 1993).

Intracellular GH signalling is suppressed by suppressors of cytokine signalling. GH induces the synthesis of 
peripheral insulin-like growth factor I (IGF-I) (Le Roith et al 2001) and endocrine, autocrine and paracrine IGF-I induces cell proliferation and is thought to inhibit apoptosis (O’Reilly et al 2006).

IGF-binding proteins (IGFBP) and their proteases regulate the access of ligands to the IGF-I receptor affecting its action. Levels of IGF-I are at their peak during late adolescence and decline throughout adulthood, mirror imaging $\mathrm{GH}$ and are determined by sex and genetic factors (Milani et al 2004). IGF-I levels reflect the secretory activity of growth hormone and is a marker for identification of GH-deficiency (GHD), or excess (Mauras and Haymond 2005). The production of IGF-I is suppressed in malnourished patients, as well as in certain disease states, such as liver disease, hypothyroidism, or poorly controlled diabetes.

In conjunction with $\mathrm{GH}$, IGF-I has varying differential effects on protein, glucose, lipid and calcium metabolism and therefore body composition (Mauras et al 2000). Direct effects result from the interaction of $\mathrm{GH}$ with its specific receptors on target cells. In the adipocyte, $\mathrm{GH}$ stimulates the cell to break down triglyceride and suppresses its ability to uptake and accumulate circulating lipids. Indirect effects are mediated primarily by IGF-I.

Little is known about the expression of skeletal musclespecific isoforms of IGF-I gene in response to exercise in humans, nor the influence of age and physical training status. A single bout of isometric exercise stimulated the expression of mRNA for the IGF-I splice variants IGF-IEa and IGF-IEc (mechano growth factor [MGF]) within 2.5 hours, which lasts for at least 2 days after exercise (Greig et al 2006).

\section{Gh deficiency (GHD)}

The therapeutic indications for recombinant human growth hormone (rhGH) in the UK are controlled by the National Institute for Clinical Excellence guidelines (NICE 2003), which has very strict guidelines and has recommended treatment with rhGH for children with:

- Growth disturbance in short children born small for gestational age

- Proven GH deficiency

- Gonadal dysgenesis (Turner's syndrome)

- Prader-Willi syndrome

- Chronic renal insufficiency before puberty (renal function decreased to less than 50\%).

Treatment should be initiated and monitored by a pediatrician with expertise in managing GH disorders; treatment can be continued under a shared-care protocol by a general practitioner. Treatment should be discontinued if the response is poor (ie, an increase in growth velocity of less than $50 \%$ from baseline) in the first year of therapy. In children with chronic renal insufficiency, treatment should be stopped after renal transplantation and not restarted for at least a year. NICE (2003) has recommended rhGH in adults only if the following three criteria are fulfilled:

- Severe GH deficiency, established by an appropriate method

- Impaired quality of life, measured by means of a specific questionnaire

- Already receiving treatment for another pituitary hormone deficiency.

Treatment should be discontinued if the quality of life has not improved sufficiently by nine months. Severe GHD developing after linear growth is complete but before the age of 25 years should be treated with rhGH; treatment should continue until adult peak bone mass has been achieved. Treatment for adult-onset GH (A-OGH) deficiency should be stopped only when the patient and the patient's physician consider it appropriate. Treatment with somatropin should be initiated and managed by a physician with expertise in $\mathrm{GH}$ disorders; maintenance treatment can be prescribed in the community under a shared-care protocol (British National Formulary 2008). A-OGH deficient individuals are overweight, with reduced lean body mass (LBM) (Salomon et al 1989; Amato et al 1993; Beshyah et al 1995) and increased fat mass (FM), especially abdominal adiposity (Salomon et al 1989; Bengtsson et al 1993; Amato et al 1993; Beshyah et al 1995; Snel et al 1995). They have reduced total body water (Black et al 1972) and reduced bone mass (Kaufman et al 1992; O’Halloran et al 1993; Holmes et al 1994). There is also reduced strength and exercise capacity (Cuneo et al 1990, 1991a, 1991b) and reduced cardiac performance and an altered substrate metabolism (Binnerts et al 1992; Fowelin et al 1993; Russell-Jones et al 1993; O'Neal et al 1994; Hew et al 1996). This leads to an abnormal lipid profile (Cuneo et al 1993; Rosen et al 1993; De Boer et al 1994; Attanasio et al 1997) which can predispose to the development of cardiovascular disease. A-OGH deficiency reduces psychological well-being and quality of life (QoL) (Stabler et al 1992; Rosen et al 1994). The use of rhGH is currently being used successfully to treat this deficiency.

\section{GH excess (acromegaly)}

$\mathrm{GH}$ excess results in the clinical condition known as acromegaly. This condition is presented as a consequence of a pituitary tumor characterized by a multitude of signs and symptoms. Pituitary tumors account for approximately $15 \%$ of 
primary intracranial tumors (Melmed 2006). Acromegalics have an increased risk of DM, hypertension and premature mortality due to CVD (Bengtsson et al 1993).

The most common side effects following administration arise from sodium and water retention.

Weight gain, dependent edema, a sensation of tightness in the hands and feet, or carpal tunnel syndrome; can frequently occur within days (Hoffman et al 1996).

Arthralgia (joint pain), involving small or large joints can occur, but there is usually no evidence of effusion, inflammation, or X-ray changes (Salomon et al 1989). Muscle pains can also occur. GH administration is documented to result in hyperinsulinemia (Hussain et al 1993) which may increase the risk of cardiovascular complications. GH-induced hypertension (Salomon et al 1989) and atrial fibrillation (Bengtsson et al 1993) have both been reported, but are rare. There have also been reports of cerebral side effects, such as encephalocele (Salomon et al 1989) and headache with tinnitus (Bengtsson et al 1993) and benign intra-cranial hypertension (Malozowski et al 1993).

Cessation of GH therapy is associated with regression of side effects in most cases (Malozowski et al 1993).

\section{APWV in pathological GH states}

The potential mechanisms accounting for this abnormality may result from a direct IGF-I mediated effect via increased production of NO. Qualitative alterations in lipoproteins have been described in GHD adults (O'Neal et al 1996), resulting in the generation of an atherogenic lipoprotein phenotype, which would contribute to endothelial dysfunction.

\section{Growth hormone deficiency (GHD)}

Increased oxidative stress exists in GHD adults, which may be a factor in atherogenesis and reduced by GH therapy's effects on oxidative stress (Evans et al 2000). Endothelial dysfunction exists in GHD adults (Evans et al 1999), which is reversible with GH replacement (Pfeifer et al 1999). An impaired endothelial-dependent dilatation (EDD) response was documented in GHD adults, which significantly improved after GH treatment.

Patients with GHD, with increased risk of vascular disease, have impaired endothelial function and increased $\mathrm{AI}^{\mathrm{x}}$ compared with controls. Replacement of GH resulted in improvement of both endothelial function and $\mathrm{AI}^{\mathrm{x}}$, without changing BP (Smith et al 2002).

Replacement of GH for 3 months corrected endothelial dysfunction in patents with chronic heart failure (Napoli et al 2002).
Renal failure induces GH resistance at the receptor and post-receptor level, with concomitant endothelial dysfunction, which can be overcome by replacement of GH (Lilien et al 2004).

\section{Growth hormone excess}

Acromegaly is associated with changes in the central arterial pressure waveform, suggesting large artery stiffening. This may have important implications for cardiac morphology and performance as well as increasing the susceptibility to atheromatous disease.

Large artery stiffness is reduced in "cured" acromegaly $\left(\mathrm{GH}<2.5 \mathrm{mU} . \mathrm{L}^{-1}\right)$ and partially reversed after pharmacological treatment of active disease (Smith et al 2003).

\section{GH and inflammatory markers of CVD}

Human peripheral blood T cells, B cells, natural killer (NK) cells, and monocytes express IGF-I receptors (Wit et al 1993). Administration of either GH or IGF-I can reverse the immunodeficiency of Snell dwarf mice (Van Buul-Offers et al 1986). GH replacement induced a significant overall increase in the percent specific lysis of K562 tumor target cells, in healthy adults (Crist and Kraner 1990). NK activity was significantly increased throughout the six weeks period of administration. In vitro studies, using human lymphocytes indicate that GH is important for the development of the immune system (Wit et al 1993). However, pre-operative administration of $\mathrm{GH}$ did not alter C-reactive protein (CRP), serum amyloid A (SAA) or interleukin-6 (IL-6, an inflammatory cytokine) release (Mealy et al 1998). Homocysteine (HCY) concentration has been established as an independent risk factor for atherosclerosis (Eichinger et al 1998; Stehouwer and Jakobs 1998). CRP and IL-6 levels and central fat decreased significantly in rhGH recipients in GHD after 18 months. Lipoprotein(a) and glucose levels significantly increased, without affecting lipid levels (Sesmilo et al 2000). HCY impairs vascular endothelial function through significant reduction of NO production. This appears to potentiate oxidative stress and atherogenic development (van Guldener and Stehouwer 2000). HCY levels were not significantly elevated in GHD adults and HCY was considered to be unlikely to be a major risk factor for vascular disease, if there are no other risk factors present (Abdu et al 2001). Pegvisomant (GH receptor antagonist) did not induce significant acute changes in the major risk markers for CVD, in apparently healthy abdominally obese men (Muller et al 2001). This suggested that the secondary 
metabolic changes, eg, inflammatory factors, which develop as a result of long-standing GHD are of primary importance in the pathogenesis of atherosclerosis in patients with GHD. Patients with active acromegaly have significantly lower CRP and significantly higher insulin levels than healthy controls and administration of pegvisomant significantly increased CRP to normal levels (Sesmilo et al 2002). GH secretory status may be an important determinant of serum CRP levels, but the mechanism and significance of this finding is as yet unknown. Inflammatory markers are predictive of atherosclerosis and cardiovascular events (Ridker et al 2002; Danesh et al 2004). The metabolic syndrome (MS) is correlated with elevated CRP and a predictor of coronary heart disease and DM (Sattar et al 2003). IL-6 concentrations were significantly increased in GHD, compared to BMI-matched and nonobese controls, respectively (Leonsson et al 2003). CRP significantly increased in patients compared to nonobese controls, but not significantly different compared to BMI-matched controls. Age, LDL-cholesterol, and IL-6 were positively correlated, and IGF-I was negatively correlated to arterial intima-media thickness (IMT) in the patient group, but only age and IL-6 were independently related to IMT.

\section{Potential mechanisms}

Oxidative stress represents a mechanism leading to the destruction of neuronal and vascular cells.

Oxidative stress occurs as a result of the production of free radicals or reactive oxygen species (ROS). ROS consist of entities including the superoxide anion, hydrogen peroxide, superoxide anion, NO, and peroxynitrite. The production of ROS, such as peroxynitrite and NO, can lead to cell injury through cell membrane lipid destruction and cleavage of DNA (Vincent and Maiese 1999). Production of excess ROS can result in the peroxidation of docosahexenoic acid (DHA), a precursor of neuroprotective docosanoids (Mukherjee et al 2004). DHA is a fatty acid released from membrane phospholipids and is derived from dietary essential fatty acids. It is involved in memory formation, excitable membrane function, photoreceptor cell biogenesis and function and neuronal signaling. DHA may have a role in modulating IGF-I binding in retinal cells (Yorek et al 1989). Neuroprotectin D1 (NPD1) is a DHA-derived mediator that protects the central nervous system (brain and retina) against cell injury-induced oxidative stress, in cerebral ischemiareperfusion. It up-regulates the anti-apoptotic $\mathrm{Bcl}-2$ proteins, $\mathrm{Bcl}-2$, and Bclxl and decreases pro-apoptotic Bax and Bad expression (Bazan 2005).
IGF-I also blocks Bcl-2 interacting mediator of cell death (Bim) induction and intrinsic death signalling in cerebellar granule neurons (Linseman et al 2002).

Dorsal root ganglia(DRG) neurons express IGF-I receptors (IGF-IR), and IGF-I activates the phosphatidylinositol 3-kinase (PI3K)/Akt pathway. High glucose exposure induces apoptosis, which is inhibited by IGF-I through the PI3K/Akt pathway. IGF-I stimulation of the PI3K/Akt pathway phosphorylates three known Akt effectors: the survival transcription factor cyclic AMP response element binding protein (CREB) and the pro-apoptotic effector proteins glycogen synthase kinase-3beta (GSK-3beta) and forkhead (FKHR). IGF-I regulates survival at the nuclear level through accumulation of phospho-Akt in DRG neuronal nuclei, increased CREB-mediated transcription, and nuclear exclusion of FKHR. High glucose levels increase expression of the pro-apoptotic Bcl protein Bim (a transcriptional target of FKHR). High glucose also induces loss of the initiator caspase- 9 and increases caspase- 3 cleavage, effects blocked by IGF-I, suggesting that IGF-I prevents apoptosis in DRG neurons by regulating $\mathrm{PI} 3 \mathrm{~K} / \mathrm{Akt}$ pathway effectors, including GSK-3beta, CREB, and FKHR, and by blocking caspase activation (Leinninger et al 2004).

The unique role of IGF-IR in maintaining the balance of death and survival in foetal brown adipocytes, in IGF-IR deficiency has been demonstrated (Valverde et al 2004).

A vascular protective role for IGF-I has been suggested because of its ability to stimulate NO production from endothelial and vascular smooth muscle cells. IGF-I probably plays a role in aging, atherosclerosis and cerebrovascular disease, cognitive decline, and dementia. In cross sectional studies, low IGF-I levels have been associated with an unfavorable profile of CVD risk factors, such as atherosclerosis, abnormal lipoprotein levels and hypertension, while in prospective studies, lower IGF-I levels predict future development of ischemic heart disease. The fall in the levels of GH (Iranmanesh et al 1991) and IGF-I (Milani et al 2004) with aging correlates with cognitive decline and it has been suggested that IGF-I plays a role in the development of dementia. IGF-I is highly expressed within the brain and is essential for normal brain development. IGF-I has anti-apoptotic and neuroprotective effects and promotes projection neuron growth, dendritic arborization and synaptogenesis (Ceda et al 2005).

\section{Conclusion}

Collectively, these data are consistent with a causal link between the age-related decline in GH and IGF-I levels and 
cardiovascular and cerebrovascular disease in senescence. Research into the benefits of replacement hormone therapy is still in its infancy. It was only three decades ago that rhGH became available and significant progress into the somatopause and related pathologies has occurred. Could the future propose the concomitant use of rhGH and rhIGF as has been used in certain refractory cases of diabetes and GH resistance (Mauras and Haymond 2005)? The reviews of $\mathrm{rhGH}$ replacement in obesity have not been revolutionary (Liu et al 2007). It might be expedient to research the combination of $\mathrm{rhGH}$ and rhIGF in the variety of physiological GHD states to determine any beneficial effects. After all, it wasn't until 1999 that hypothyroidism was identified as being more appropriately treated with tri-iodothyronine $\left(\mathrm{T}_{3}\right)$ and tetra-iodothyronine $\left(\mathrm{T}_{4}\right)$, than $\mathrm{T}_{4}$ alone (Bunevicius et al 1999).

\section{Disclosure}

The authors report no conflicts of interest in this work.

\section{References}

Abdu TA, Elhadd TA, Akber M, et al. 2001. Plasma homocysteine is not a major risk factor for vascular disease in growth hormone deficient adults. Clin Endocrinol (Oxf), 55:635-8.

Amato G, Carella C, Fazio S, et al. 1993. Body composition, bone metabolism, and heart structure and function in growth hormone $(\mathrm{GH})$-deficient adults before and after GH replacement therapy at low doses. J Clin Endocrinol Metab, 77:1671-6.

Argetsinger LS, Campbell GS, Yang X, et al. 1993. Identification of JAK2 as a growth hormone receptor-associated tyrosine kinase. Cell, 74:237-44.

Asmar R, Benetos A, Topouchian J, et al. 1995. Assessment of arterial distensibility by automatic pulse wave velocity measurement. Validation and clinical application studies. Hypertension, 26:485-90.

Attanasio AF, Lamberts SW, Matranga AM, et al. 1997. Adult growth hormone-deficient patients demonstrate heterogeneity between childhood onset and adult onset before and during human GH treatment. J Clin Endocrinol Metab, 82:82-8.

Avolio AP, Chen SG, Wang RP, et al. 1983. Effects of ageing on changing arterial compliance and left ventricular load in a northern Chinese urban community. Circulation, 68:50-8.

Avolio A, Jones D, Tafazzoli-Shadpour M. 1998. Quantification of alterations in structure and function of elastin in the arterial media. Hypertension, 32:170-5.

Balkestein EJ, Staessen JA, Wang JG, et al. 2001. Carotid and femoral artery stiffness in relation to three candidate genes in a white population. Hypertension, 38:1190-7.

Bank AJ, Wang H, Holte JE, et al. 1996. Contribution of collagen, elastin, and smooth muscle to in vivo human brachial artery wall stress and elastic modulus. Circulation, 94:3263-70.

Bank AJ, Kaiser DR, Rajala S, et al. 1999. In vivo human brachial artery elastic mechanics: effects of smooth muscle relaxation. Circulation, 100:41-7.

Baumann G. 1991. Growth hormone heterogeneity: genes, isohormones, variants, and binding proteins. Endocr Rev, 12:424-9.

Bazan NG. 2005. Neuroprotectin D1 (NPD1): a DHA-derived mediator that protects brain and retina against cell injury-induced oxidative stress. Brain Pathol, 15:159-66.
Benetos A, Adamopoulos C, Bureau JM, et al. 2002. Determinants of accelerated progression of arterial stiffness in normotensive subjects and in treated hypertensive subjects over a 6-year period. Circulation, 105:1202-7.

Bengtsson BA, Eden S, Lonn L, et al. 1993. Treatment of adults with growth hormone $(\mathrm{GH})$ deficiency with recombinant human $\mathrm{GH}$. J Clin Endocrinol Metab, 76:309-17.

Berenson GS, Wattigney WA, Tracy RE, et al. 1992. Atherosclerosis of the aorta and coronary arteries and cardiovascular risk factors in persons aged 6 to 30 years and studied at necropsy (The Bogalusa Heart Study). Am J Cardiol, 70:851-8.

Bertovic DA, Waddell TK, Gatzka CD, et al. 1999. Muscular strength training is associated with low arterial compliance and high pulse pressure. Hypertension, 33:1385-91.

Beshyah SA, Freemantle C, Shahi M, et al. 1995. Replacement treatment with biosynthetic human growth hormone in growth hormone-deficient hypopituitary adults. Clin Endocrinol (Oxf), 42:73-84.

Binnerts A, Swart GR, Wilson JHP, et al. 1992. The effect of growth hormone administration in growth hormone-deficient adults on bone, protein, carbohydrate and lipid homeostasis, as well as body composition. Clin Endocrinol, 37:79-87.

Blacher J, Asmar R, Djane S, et al. 1999a. Aortic pulse wave velocity as a marker of cardiovascular risk in hypertensive patients. Hypertension, 33:1111-7.

Blacher J, Guerin AP, Pannier B, et al. 1999b. Impact of aortic stiffness on survival in end-stage renal disease. Circulation, 99:2434-9.

Black MM, Shuster S, Bottoms E. 1972. Skin collagen and thickness in acromegaly and hypopituitarism. Clin Endocrinol, 1:259-63.

Boutouyrie P, Tropeano AI, Asmar R, et al. 2002. Aortic stiffness is an independent predictor of primary coronary events in hypertensive patients: a longitudinal study. Hypertension, 39:10-5.

Bramwell JC, Hill AV. 1922. The velocity of the pulse wave in man. Proc R Soc Lond B Biol Sci, 93:298-306.

Bramwell JC, Hill AV, McSwiney BA. 1923. The velocity of the pulse wave in man in relation to age as measured by the hot wire sphygmograph. Heart, 10:233-55.

Brinton TJ, Kailasam MT, Wu RA, et al. 1996. Arterial compliance by cuff sphygmomanometer; Application to hypertension and early changes in subjects at genetic risk. Hypertension, 28:599-603.

British National Formulary. 2008. A joint publication of the British Medical Association and the Royal Pharmaceutical Society of Great Britain. BMJ Group and RPS Publishing [online]. Accessed Jan 18, 2008. URL: http://www.bnf.org.uk/.

Brown RJ, Adams JJ, Pelekanos RA, et al. 2005. Model for growth hormone receptor activation based on subunit rotation within a receptor dimer. Nat Struct Mol Biol, 12:814-21.

Busse R, Pohl U. 1993. Fluid shear-stress-dependent stimulation of endothelial cell autacoid release: mechanisms and significance for the control of vascular tone. In: Frangos JA, Ives CL (eds). Physical Forces and the Mammalian Cell. Orlando, FL: Academic Press, p. 223-48.

Bunevicius R, Kazanavicius K, Zalinkevicius R, et al. 1999. Effects of thyroxine as compared with thyroxine plus triiodothyronine in patients with hypothyroidism. $N$ Engl J Med, 340:424-9.

Ceda GP, Dall'Aglio E, Maggio M, et al. 2005. Clinical implications of the reduced activity of the GH-IGF-I axis in older men. J Endocrinol Invest, 28 96-100.

Cocks TM, Angus JA, Campbell JH, et al. 1985. Release and properties of endothelium-derived relaxing factor (EDRF) from endothelial cells in culture. J Cell Physiol, 123:310-20.

Cohn JN, Finkelstein S, McVeigh G, et al. 1995. Non-invasive pulse wave analysis for the early detection of vascular disease. Hypertension, 26:503-8.

Crist DM, Kraner JC. 1990. Supplemental growth hormone increases the tumor cytotoxic activity of natural killer cells in healthy adults with normal growth hormone secretion. Metabolism, 39:1320-4.

Cuneo RC, Salomon F, Wiles CM, Sonksen PH. 1990. Skeletal muscle performance in adults with growth hormone-deficiency. Hormone Res, 33:55-60. 
Cuneo RC, Salomon F, Wiles CM, et al. 1991a. Growth hormone treatment in growth hormone-deficient adults. I. Effects on muscle mass and strength. J Appl Physiol, 70:688-94.

Cuneo RC, Salomon F, Wiles CM, et al. 1991b. Growth hormone treatment in growth hormone-deficient adults. II. Effects on exercise performance. J Appl Physiol, 70:695-700.

Cuneo RC, Salomon F, Wilmshurst P, et al. 1991c. Cardiovascular effects of growth hormone treatment in growth-hormone-deficient adults: stimulation of the renin-aldosterone system. Clin Sci (Lond), 81:587-92.

Cuneo RC, Salomon F, Wiles CM, et al. 1993. Growth hormone treatment improves serum lipids and lipoproteins in adults with growth hormonedeficiency. J Clin Endocrinol Metab, 42:1519-23.

Danesh J, Wheeler JG, Hirschfield GM, et al. 2004. C-reactive protein and other circulating markers of inflammation in the prediction of coronary heart disease. N Engl J Med, 350:1387-97.

De Boer H, Blok GJ, Voerman HJ, et al. 1994. Serum lipid levels in growth hormone-deficient men. J Clin Endocrinol Metab, 43:199-203.

Eichinger S, Stumpflen A, Hirschl M, et al. 1998. Hyperhomocysteinemia is a risk factor of recurrent venous thromboembolism. Thromb Haemost, 80:566-9.

Evans LM, Davies JS, Anderson RA, et al. 2000. The effect of GH replacement on endothelial function and oxidative stress in adult growth hormone deficiency. Eur J Endocrinol, 142:254-62.

Evans LM, Davies JS, Goodfellow J, et al. 1999. Endothelial dysfunction in hypopituitary adults with growth hormone deficiency. Clin Endocrinol, 50:457-64.

Ferrier KE, Waddell TK, Gatzka CD, et al. 2001. Aerobic exercise training does not modify large-artery compliance in isolated systolic hypertension. Hypertension, 38:222-6.

Ferrier KE, Muhlmann MH, Baguet JP, et al. 2002. Intensive cholesterol reduction lowers blood pressure and large artery stiffness in isolated systolic hypertension. J Am Coll Cardiol, 39:1020-5.

Förstermann U, Nakane M, Tracey WR, et al. 1993. Isoforms of nitric oxide synthase: functions in the cardiovascular system. Eur Heart $J$, 14:10-5.

Fowelin J, Attvall S, Lager I, et al. 1993. Effects of treatment with recombinant human growth hormone on insulin sensitivity and glucose metabolism in adults with growth hormone deficiency. Metab Clin Exper, 42:1443-7.

Furchgott RF. 1984. The role of endothelium in the responses of vascular smooth muscle to drugs. Ann Rev Pharmacol Toxicol, 24:175-97.

Giannattasio C, Cattaneo BM, Mangoni AA, et al. 1992. Changes in arterial compliance induced by physical training in hammer-throwers. JHypertens, 10:53-5.

Giannattasio C, Vincenti A, Failla M, et al. 2003. Effects of heart rate changes on arterial distensibility in humans. Hypertension, 42:253-6.

Greenfield JC, Patel DJ. 1962. Relation between pressure and diameter in the ascending aorta of man. Circ Res, 10:778-81.

Greig CA, Hameed M, Young A, et al. 2006. Skeletal muscle IGF-I isoform expression in healthy women after isometric exercise. Growth Horm IGF Res, 16:373-6.

Guerin AP, Blacher J, Pannier B, et al. 2001. Impact of aortic stiffness attenuation on survival of patients in end-stage renal failure. Circulation, 103:987-92.

Hallock P, Benson IC. 1937. Studies on the elastic properties of human isolated aorta. $J$ Clin Invest, 16:595-602.

Hew FL, Koschmann M, Christopher M, et al. 1996. Insulin resistance in growth hormone-deficient adults: defects in glucose utililization and glycogen synthase activity. J Clin Endocrinol Metab, 81:555-64.

Hoffman DM, Crampton I, Sernia C. 1996. Short term growth hormone (GH) treatment of GH deficient adults increases body sodium and extracellular water, but not blood pressure. J Clin Endocrinol Metab, 81:1123-8.

Holmes SJ, Economou G, Whitehouse RW, et al. 1994. Reduced bone mineral density in patients with growth hormone deficiency. J Clin Endocrinol Metab, 78:669-74.
Hussain MA, Schmitz O, Mengel A, et al. 1993. Insulin-like growth factor I stimulates lipid oxidation, reduces protein oxidation, and enhances insulin sensitivity in humans. J Clin Invest, 92:2249-56.

Iranmanesh A, Lizarralde G, Velduis JD. 1991. Age and relative adiposity are specific negative determinants of the frequency and amplitude of growth hormone secretory bursts and the half-life of endogenous GH in healthy men. J Clin Endocrinol Metab, 73:1081-8.

Joannides R, Richard V, Haefeli WE, et al. 1997. Role of nitric oxide in the regulation of the mechanical properties of peripheral conduit arteries in humans. Hypertension, 30:1465-70.

Kaufman JM, Taelman P, Vermeuelen A, et al. 1992. Bone mineral status in growth hormone-deficient males with isolated and multiple pituitary insufficiencies of childhood onset. J Clin Endocrinol Metab, 74:118-23.

Kelly RP, Millasseau SC, Ritter JM, et al. 2001. Vasoactive drugs influence aortic augmentation index independently of pulse-wave velocity in healthy men. Hypertension, 37:1429-33.

Kingwell BA, Cameron JD, Gillies KJ, et al. 1995. Arterial compliance may influence baroreflex function in athletes and hypertensives. $\mathrm{Am}$ $J$ Physiol, 268:411-8.

Kingwell BA, Berry KL, Cameron JD, et al. 1997a. Arterial compliance increases after moderate-intensity cycling. Am J Physiol, 273:2186-91.

Kingwell BA, Sherrard B, Jennings GL, et al. 1997b. Four weeks of cycle training increases basal production of nitric oxide from the forearm. Am J Physiol, 272:1070-7.

Kinlay S, Creager MA, Fukumoto M, et al. 2001. Endothelium-derived nitric oxide regulates arterial elasticity in human arteries in vivo. Hypertension, 38:1049-53.

Kroeker EJ, Wood EH. 1955. Comparison of simultaneously recorded central and peripheral arterial pressure pulses during rest, exercise and tilted position in man. Circ Res, 3:623-32.

Lajemi M, Gautier S, Poirier O, et al. 2001a. Endothelin gene variants and aortic and cardiac structure in never-treated hypertensives. Am J Hypertens, 14:755-60.

Lajemi M, Labat C, Gautier S, et al. 2001b. Angiotensin II type I receptor$153 \mathrm{~A} / \mathrm{G}$ and $1166 \mathrm{~A} / \mathrm{C}$ gene polymorphisms and increase in aortic stiffness with age in hypertensive subjects. J Hypertens, 19:407-13.

Lantelme P, Mestre C, Lievre M, et al. 2002. Heart rate. An important confounder of pulse wave velocity assessment. Hypertension, 39:1083-7.

Laogun AA, Gosling RG. 1982. In vivo arterial compliance in man. Clin Phys Physiol Meas, 3:201-12.

Laurent S, Boutouyrie P, Asmar R, et al. 2001. Aortic stiffness is an independent predictor of all-cause and cardiovascular mortality in hypertensive patients. Hypertension, 37:1236-41.

Lehmann ED, Watts GF, Gosling RG. 1992a. Aortic distensibility and hypercholesterolaemia. Lancet, 340:1171-2.

Lehmann ED, Gosling RG, Sonksen PH. 1992b. Arterial wall compliance in diabetes. Diabet Med, 9:114-9.

Lehmann ED, Hopkins KD, Rawesh A, et al. 1998. Relation between number of cardiovascular risk factors/events and non-invasive Doppler ultrasound assessments of aortic compliance. Hypertension, 32:565-9.

Lehmann ED. 1999. Non-invasive measurements of aortic stiffness: methodological considerations. Pathol Biol (Paris). 47:716-30.

Leinninger GM, Backus C, Uhler MD, et al. 2004. Phosphatidylinositol 3-kinase and Akt effectors mediate insulin-like growth factor-I neuroprotection in dorsal root ganglia neurons. FASEB J, 18:1544-6.

Leonsson M, Hulthe J, Johannsson G, et al. 2003. Increased interleukin-6 levels in pituitary-deficient patients are independently related to their carotid intima-media thickness. Clin Endocrinol, (Oxf). 59:242-50.

Le Roith D, Scavo L, Butler A. 2001. What is the role of circulating IGF-I? Trends Endocrinol Metab, 12:48-52.

Lilien MR, Schroder CH, Levtchenko EN, et al. 2004. Growth hormone therapy influences endothelial function in children with renal failure. Pediatr Nephrol, 19:785-9.

Linseman DA, Phelps RA, Bouchard RJ, et al. 2002. Insulin-like growth factor-I blocks Bcl-2 interacting mediator of cell death (Bim) induction and intrinsic death signaling in cerebellar granule neurons. J Neurosci, 22:9287-97. 
Liu H, Bravata DM, Olkin I, et al. 2007. Systematic review: the safety and efficacy of growth hormone in the healthy elderly. Ann Intern Med, 16:104-15.

Malozowski S, Tanner LA, Wysowski D, et al. 1993. Growth hormone, insulin-like growth factor I, and benign intracranial hypertension. N Engl J Med, 329:665-6.

Mauras N, Haymond MW. 2005. Are the metabolic effects of GH and IGF-I separable. Growth Horm and IGF Res, 15:19-27.

Mauras N, Attie KM, Reiter EO, et al. 2000. High dose recombinant human growth hormone $(\mathrm{GH})$ treatment of GH-deficient patients in puberty increases near-final height: a randomized, multicenter trial. Genentech, Inc., Cooperative Study Group. J Clin Endocrinol Metab, 85:3653-60.

McLeod AL, Uren NG, Wilkinson IB, et al. 2004. Non-invasive measures of pulse wave velocity correlate with coronary arterial plaque load in humans. J Hypertens, 22:363-8.

Mealy K, Barry M, O’Mahony L, et al. 1998. Effects of human recombinant growth hormone $(\mathrm{rhGH})$ on inflammatory responses in patients undergoing abdominal aortic aneurysm repair. Intensive Care Med, 24:128-31.

Meaume S, Benetos A, Henry OF, et al. 2001. Aortic pulse wave velocity predicts cardiovascular mortality in subjects $>70$ years of age. Arterioscler Thromb Vasc Biol, 21:2046-50.

Medley TL, Cole TJ, Gatzka CD, et al. 2002. Fibrillin-1 genotype is associated with aortic stiffness and disease severity in patients with coronary artery disease. Circulation, 105:810-5.

Melmed S. 2006. Medical progress: Acromegaly. N Engl J Med, 14:2558-73.

Meredith IT, Currie KE, Anderson TJ, et al. 1996. Post ischemic vasodilation in human forearm is dependent on endothelium-derived nitric oxide. Am J Physiol, 270:1435-40.

Milani D, Carmichael JD, Welkowitz J, et al. 2004. Variability and reliability of single serum IGF-I measurements: impact on determining predictability of risk ratios in disease development. J Clin Endocrinol Metab, 89:2271-4.

Miyachi M, Donato AJ, Yamamoto K, et al. 2003. Greater age-related reductions in central arterial compliance in resistance-trained men. Hypertension, 41:130-5.

Miyachi M, Kawano H, Sugawara J, et al. 2004. Unfavourable effects of resistance training on central arterial compliance. A randomized intervention study. Circulation, 110:2858-63.

Mohiaddin RH, Underwood SR, Bogren HG, et al. 1989. Regional aortic compliance studied by magnetic resonance imaging: the effects of age, training and coronary artery disease. Br Heart J, 62:90-6.

Moncada S, Palmer RMJ, Higgs EA. 1991. Nitric oxide: physiology, pathophysiology and pharmacology. Pharmacol Rev, 43:109-42.

Mukherjee PK, Marcheselli VL, Serhan CN, et al. 2004. Neuroprotectin D1: a docosahexaenoic acid-derived docosatriene protects human retinal pigment epithelial cells from oxidative stress. Proc Natl Acad Sci U S A, 101:8491-6.

Muller AF, Leebeek FW, Janssen JA, et al. 2001. Acute effect of pegvisomant on cardiovascular risk markers in healthy men: implications for the pathogenesis of atherosclerosis in GH deficiency. $J$ Clin Endocrinol Metab, 86:5165-71.

Naka KK, Tweddel AC, Parthimos D, et al. 2003. Arterial distensibility: acute changes following dynamic exercise in normal subjects. Am J Physiol Heart Circ Physiol, 284:970-8.

Napoli R, Guardasole V, Matarazzo M, et al. 2002. Growth hormone corrects vascular dysfunction in patients with chronic heart failure. $J$ Am Coll Cardiol, 39:90-5.

Newby AC, Henderson AH. 1990. Stimulus-secretion coupling in vascular endothelial cells. Ann Rev Physiol, 52:661-74.

[NICE] The National Institute for Health and Clinical Excellence. 2003. The National Institute for Health and Clinical Excellence [online]. Published by the Health Development Agency. Accessed Jan 18, 2008. URL: http://www.nice.org.uk.

Nichols WW, O’Rourke MF. 1998. Wave reflections. In: McDonald's Blood Flow in Arteries: Theoretical, Experimental and Critical Principles. London: Edward Arnold.
O’Halloran DJ, Tsatsoulis A, Whitehouse RW, et al. 1993. Increased bone density after recombinant human growth hormone therapy in adults with isolated GH deficiency. J Clin Endocrinol Metab, 76:1344-8.

Oliver JJ, Webb DJ. 2003. Non-invasive assessment of arterial stiffness and risk of atherosclerotic events. Arterioscler Thromb Vasc Biol, 23:554-66.

O'Neal DN, Kalfas A, Dunning PL, et al. 1994. The effect of 3 months of recombinant human growth hormone $(\mathrm{GH})$ therapy on insulin and glucose-mediated glucose disposal and insulin secretion in GH-deficient adults: a minimal model analysis. J Clin Endocrinol Metab, 79:975-83.

O’Neal D, Few FL, Sikaris K, et al. 1996. Low density lipoprotein particle size in hypopituitary adults receiving conventional growth hormone replacement therapy. J Clin Endocrinol Metab, 81:2448-54.

O'Reilly KE, Rojo F, She QB, et al. 2006. mTOR inhibition induces upstream receptor tyrosine kinase signaling and activates Akt. Cancer Res, 66:1500-8.

O'Rourke MF. 1992. Arterial mechanics and wave reflection with antihypertensive therapy. J Hypertens Suppl, 10:43-9.

O'Rourke MF. 1999. Wave travel and reflection in the arterial system. J Hypertens, 17:45-7.

O'Rourke MF, Pauca A, Jiang XJ. 2001. Pulse wave analysis. Br J Clin Pharm, 51:507-22.

O’Rourke MF, Staessen JA, Vlachopoulos C, et al. 2002. Clinical applications of arterial stiffness; definitions and reference values. $\mathrm{Am}$ J Hypertens, 15:426-44.

Pfeifer M, Verhovec M, Zizek B, et al. 1999. Growth hormone (GH) treatment reverses early atherosclerotic changes in $\mathrm{GH}$-deficient adults. $J$ Clin Endocrinol Metab, 84:453-7.

Pohl U, Holtz J, Busse R, et al. 1986. Crucial role of endothelium in the vasodilator response to increased flow in vivo. Hypertension, 8:37-47.

Ramsey MW, Goodfellow J, Jones CJH, et al. 1995. Endothelial control of arterial distensibility is impaired in chronic heart failure. Circulation, 92:3212-9.

Ridker PM, Rifai N, Rose L, et al. 2002. Comparison of C-reactive protein and low-density lipoprotein cholesterol levels in the prediction of first cardiovascular events. $N$ Engl J Med, 347:1557-65.

Riley WA, Freedman DS, Higgs NA, et al. 1986. Decreased arterial elasticity associated with cardiovascular disease risk factors in the young. The Bogalusa Heart Study. Arteriosclerosis, 6:378-86.

Rosen T, Eden S, Larson G, et al. 1993. Cardiovascular risk factors in adult patients with growth hormone deficiency. Acta Endocrinol, 129:195-200.

Rosen T, Wiren L, Wilhelmsen L, et al. 1994. Decreased psychological well-being in adult patients with growth hormone deficiency. Clin Endocrinol, 40:111-6.

Rowell LB, Brengelmann GL, Blackmon JR, et al. 1968. Disparities between aortic and peripheral pulse pressures induced by upright exercise and vasomotor changes in man. Circulation, 37:954-64.

Russell-Jones DL, Weissberger AJ, Bowes SB, et al. 1993. The effects of growth hormone on protein metabolism in adult growth hormonedeficient patients. Clin Endocrinol, 38:427-31.

Safar ME, Blacher J, Pannier B, et al. 2002. Central pulse pressure and mortality in end-stage renal disease. Hypertension, 39:735-8.

Salomon F, Cuneo RC, Hesp R, et al. 1989. The effects of treatment with recombinant human growth hormone on body composition and metabolism in adults with growth hormone deficiency. N Engl J Med, 321:1797-803.

Sattar N, Gaw A, Scherbakova O, et al. 2003. Metabolic syndrome with and without $\mathrm{C}$-reactive protein as a predictor of coronary heart disease and diabetes in the West of Scotland Coronary Prevention Study. Circulation, 108:414-9.

Sesmilo G, Biller BM, Llevadot J, et al. 2000. Effects of growth hormone administration on inflammatory and other cardiovascular risk markers in men with growth hormone deficiency. A randomized, controlled clinical trial. Ann Intern Med, 133:111-22.

Sesmilo G, Fairfield WP, Katznelson L, et al. 2002. Cardiovascular risk factors in acromegaly before and after normalization of serum IGF-I levels with the GH antagonist pegvisomant. J Clin Endocrinol Metab, $87: 1692-9$. 
Smith JC, Evans LM, Wilkinson I, et al. 2002. Effects of GH replacement on endothelial function and large-artery stiffness in GH-deficient adults: a randomized, double-blind, placebo-controlled study. Clin Endocrinol, 56:493-501.

Smith JC, Lane H, Davies N, et al. 2003. The effects of depot long-acting somatostatin analog on central aortic pressure and arterial stiffness in acromegaly. J Clin Endocrinol Metab, 88:2556-61.

Snel YE, Doerga ME, Brummer RM, et al. 1995. Magnetic resonance imaging-assessed adipose tissue and serum lipid and insulin concentrations in GHD adults. Effect of growth hormone replacement. Arterioscler Thromb Vasc Biol, 15:1543-8.

Stabler B, Turner JR, Girdler SS, et al. 1992. Reactivity to stress and psychological adjustment in adults with pituitary insufficiency. Clin Endocrinol, 6:467-73.

Stehouwer CD, Jakobs C. 1998. Abnormalities of vascular function in hyperhomocysteinaemia: relationship to atherothrombotic disease. Eur J Pediatr, 157:107-11.

Stewart AD, Millasseau SC, Kearney MT, et al. 2003. Effects of inhibition of basal nitric oxide synthesis on carotid-femoral pulse wave velocity and augmentation index in humans. Hypertension, 42:915-8.

Sutton-Tyrrell K, Mackey RH, Holubkov R, et al. 2001. Measurement variation of aortic pulse wave velocity in the elderly. Am J Hypertens, $14: 463-8$.

Tomiyama H, Yamashina A, Arai T, et al. 2003. Influences of age and gender on results of non-invasive brachial-ankle pulse wave velocity measurement/a survey of 12,517 subjects. Atherosclerosis, 166:303-9.

Vaitkevicius PV, Fleg JL, Engel JH, et al. 1993. Effects of age and aerobic capacity on arterial stiffness in healthy adults. Circulation, 88:1456-62.

Valverde AM, Mur C, Brownlee M, et al. 2004. Susceptibility to apoptosis in insulin-like growth factor-I receptor-deficient brown adipocytes. Mol Biol Cell, 15:5101-17.

Van Buul-Offers S, Ujeda I, Van den Brande JL. 1986. Biosynthetic somatomedin $\mathrm{C}$ increases the length and weight of Snell dwarf mice. Paediatric Res, 20:825-77.
Van Doornum S, McColl G, Wicks IP. 2004. Atorvastatin reduces arterial stiffness in patients with rheumatoid arthritis. Ann Rheum Dis, 63:1571-5.

Van Guldener C, Stehouwer CD. 2000. Hyperhomocysteinemia, vascular pathology, and endothelial dysfunction. Semin Thromb Hemost, 26:281-9.

Vincent AM, Maiese K. 1999. Nitric oxide induction of neuronal endonuclease activity in programmed cell death. Exp Cell Res, 246:290-300.

Wenn CM, Newman DL. 1990. Arterial tortuosity. Australas Phys Eng Sci Med, 13:67-70.

Westerbacka J, Wilkinson I, Cockcroft J, et al. 1999. Diminished wave reflection in the aorta: a novel physiological action of insulin on large blood vessels. Hypertension, 33:1118-22.

Wilkinson IB, Fuchs SA, Jansen IM, et al. 1998b. Reproducibility of pulse wave velocity and augmentation index measured by pulse wave analysis. J Hypertens, 16:2079-84.

Wilkinson IB, Webb DJ, Cockcroft JR. 1999. Aortic pulse-wave velocity. Lancet, 354:1996-7.

Wilkinson IB, MacCallum H, Hupperetz PC, et al. 2001. Changes in the derived central pressure waveform and pulse pressure in response to angiotensin II and nor-adrenaline in man. $J$ Physiol, 530:541-50.

Wilkinson IB, Hall IR, MacCallum H, et al. 2002a. Pulse-wave analysis: clinical evaluation of a non-invasive, widely applicable method for assessing endothelial function. Arterioscler Thromb Vasc Biol, 22:147-52.

Wilkinson IB, Quasem A, McEniery CM, et al. 2002b. Nitric oxide regulates local arterial distensibility in vivo. Circulation, 105:213-7.

Wit JM, Kooijman R, Rijkers GT, et al. 1993. Immunological findings in growth hormone treated patients. Hormone Res, 39:107-10.

Yaginuma T, Avolio A, O’Rourke MF. 1986. Effects of glyceryl trinitrate on peripheral arteries alters left ventricular hydraulic load in man. Circ Res, 20:153-60.

Yorek M, Leeney E, Dunlap J, et al. 1989. Effect of fatty acid composition on insulin and IGF-I binding in retinoblastoma cells. Invest Ophthalmol Vis Sci, 30:2087-92. 
